\title{
Título: Da Crítica Feminista e a Escrita Feminina
}

\author{
A U T O R A : Paula Cristina Ribeiro da Rocha de Morais Cunha*
}

RESUMO: A crítica feminista constituiu-se como um modelo conceitual de questionamento da cultura dominante, mas também uma prática de leitura e análise da produção de autoria feminina. Tendo no centro do debate teórico a questão da diferença sexual e da existência de uma escrita feminina, a ginocrítica propõe a redefinição dos pressupostos de uma cultura que impôs um paradigma que manteve a mulher afastada da produção simbólica. Este trabalho enuncia algumas dessas questões.

PALAVRAS - CHAVE: Crítica feminista, escrita feminina, Novas cartas portuguesas

AB STRACT: The feminist critique is a conceptual model for questioning the dominant culture, but it is also a practice of reading and analyzing the production of female authorship. Having in the center of theoretical debate the question of sexual difference and women's writing, gynocritics proposes to redefine the assumptions of a culture that has imposed a paradigm which has kept women away from the symbolic production. This paper sets out some of these issues.

KEYWORDS : Feminist criticism, women's writing, Novas cartas portuguesas

Mas o que pode a literatura? Ou antes: o que podem as palauras?

Que tempo? O nosso tempo. E que arma, que arma utilizamos ou desprezamos nós? Em que refúgio nos abrigamos ou que luta é a nossa enquanto apenas no domínio da palaura?

Maria Isabel Barreno, Maria Teresa Horta, Maria Velho da Costa,

Novas cartas portuguesas Eu quero escrever com o vigor de uma mulher. Não me interessa escrever como homem.

Lya Luft, Escrever mulheres

Depois de uma primeira vaga dos movimentos feministas, em que as mulheres lutaram pelo reconhecimento de direitos legais e cívicos fundamentais, como o direito ao voto, à educação, à igualdade de acesso e de oportunidades no universo trabalhista, assistiu-se a um alargamento do âmbito da intervenção feminina, designadamente na esfera da construção simbólica, com a publicação de importantes livros como The feminine mystique (1963), de Betty Friedan, Sexual politics (1969), de Kate Millet, The female eunuch (1970), de Germaine Greer, e The dialectic of sex (1970), de Shulamith Firestone, nos quais eram desenvolvidas questões levantadas, vinte anos antes, por Simone de Beauvoir, em Le deuxième sexe (1949). A famosa afirmação "On ne naît pas femme, on le devient" tornar-se-á o mote para discussões em torno da diferença sexual, da alteridade e da discriminação cultural das mulheres, graças à ideologia patriarcal, que as considerava incapazes de criação estética.

A crítica feminista nasceu da necessidade de privilegiar o olhar e a perspectiva hermenêutica feminina na abordagem de textos canônicos, quer salientando a representação da mulher nessa literatura androcêntrica, na qual era idealizada (mulher anjo) ou diabolizada (mulher fatal, bruxa, decaída), mas sempre dela prevalecendo imagens estereotipadas. A abordagem metodológica

* Doutoranda, Universidade Federal da Paraíba (UFPB), sob orientação da Professora Doutora Nadilza Barros Moreira. pcrisrocha@gmail.com 
que num segundo momento se esforçou por reabilitar obras de autoria de mulheres, com o ensejo de estabelecer genealogias femininas, implicando o questionamento do cânone e do seu estabelecimento, isto é, das instâncias de consagração dos paradigmas literários, é designada por Elaine Showalter de ginocrítica. Reescrever a história literária, propor revisões do cânone, implicou valorizar a diferença sexual. No entanto, se a questão do gênero ganha em ser perspectivada como construção social, como socialmente produzidas as diferenças sexuais, continua a preponderar uma concepção monolítica das identidades masculinas ou femininas. Na verdade, na base do essencialismo no processo de socialização dos gêneros, está a diferença biológica. A distinção entre sex, que assenta na componente biológica, e gender, significando a construção de identidades sexuais, constitui uma das ideias fundamentais para a crítica feminista anglo-americana e possui a vantagem metodológica de distinguir o fato biológico do construto social. Porém, como adverte Bonnie Mcelhinny, em "Theorizing gender in sociolinguistic and linguistic anthropology", "often implicit in such distinctions is the idea that what is socially constructed (gender) can be more easily transformed than what is biological (sex)." (Mcelhinny, 2004, p. 23) Por detrás da ideia de aprendizagem dos papéis sociais, escondem-se motivações ideológicas. O conceito de gênero estabelece a constituição das identidades masculinas ou femininas numa lógica relacional, isto é, definindo-se uma em função da outra: "'gender' as a way of referring to the social organization between sexes." (Scott, 1986, p. 1053) Ao dissociar sex e gender, ao colocar-se a tônica no sistema de relações que não estão necessariamente ligadas ao sexo, promove-se, no entanto, uma visão da história polarizada e legitimam-se abordagens epistemológicas que ratificam os paradigmas históricos existentes, em vez de se sugerirem paradigmas alternativos. Segundo Joan Scott, a tendência descritiva da escrita da história, que reserva um tratamento à parte do percurso histórico das mulheres, não problematiza a construção social dos papéis sexuais nem se propõe explicar por que razão se estabeleceram de determinada maneira ou que relação mantêm com o poder, com a manutenção das políticas sociais ou sua alteração ao longo do processo histórico.A teoria lacaniana concede à linguagem um papel central na introdução da criança à ordem simbólica: é pela linguagem que a criança comunica, representa o mundo, articula as relações com aqueles que a rodeiam, mas também compreende como a sociedade representa o gênero. A identidade de gênero é produzida pela linguagem, no sentido em que está implicada num sistema de significação que regula as relações humanas. A aprendizagem de papéis sexuais é mediada pela linguagem, encontrando significação numa lógica relacional. O processo de identificação com os papéis masculino ou feminino tem sentido dentro desse sistema simbólico:
Like words themselves, subjective identities are processes of differentiation and distinction, requiring the supression of ambiguities and opposite elements in order to assure (and create the illusion of) coherence and common understanding. The idea of masculinity rests on the necessary repression of feminine aspects - of the subject's potential for bisexuality - and introduces conflict into the opposition of masculine and feminine. Repressed desires are present in the unconscious and are constantly a threat to the stability of gender identity, denying its unity, subverting its need for security. (Scott, 1986, p. 1063)

Conforme Joan Scott, o modelo lacaniano padece, no entanto, de uma visão reducionista, ao basear os seus pressupostos epistemológicos em identificações sexuais rígidas que dependem da subjetividade, em vez de conceber a construção da identidade como processo. Para a teoria queer, que corresponde a uma terceira vaga dos estudos feministas, a concepção de gênero como performatividade desafia a de gênero como atributo, isto é, de identidade sexual dada à partida, atribuída em função do sexo, para se conceber como identidade que se constrói, que não é estável, e que, portanto, é passível de mudança. Não obstante, no padrão de Lacan, 
ficam cristalizadas as categorias de homem e mulher e dos papéis que devem assumir dentro do sistema social que codifica os seus comportamentos e os dota de significado em relação a esse modelo. As categorias binárias conduzem ao essencialismo, se não se levar em conta os contextos em que se produzem os comportamentos e que razões ideológicas levaram a que se produzissem dessa forma. Joan Scott diz, ainda, que "by insisting on fixed differences (...), feminists contribute to the kind of thinking they want to oppose. Although they insist on their evaluation of the category "female" (...), they do not examine the binary opposition itself." (Scott, 1986, p. 1065) E propõe que se proceda a uma "genuine historicization and deconstruction of the terms of sexual difference". (Scott, 1986, p.: 1065) Tal naturalização das identidades sexuais deve ser questionada, com o objetivo de se desconstruir o processo mesmo dessa apropriação cultural em função da biologia. Especificamente, o que Joan Scott preconiza é que o gênero enquanto categoria analítica se constitua numa forma de falar sobre "systems of social or sexual relations". (Scott, 1986, p. 1066) Por isso, o paradoxo na concepção de gênero como construção reside na suspensão que consiste em conceber as identidades sexuais como categorias fixas, naturalizadas, com origem em si mesmas, sem atender a processos de legitimação dessa construção que se sustentam na diferença sexual para justificar formas de poder, nomeadamente o domínio masculino:

Gender is one of the recurrent references by which political power has been conceived, legitimated, and criticized. It refers to but also establishes the meaning of the male / female opposition. To vindicate political power, the reference must seem sure and fixed, outside human construction, part of the natural or divine order. (Scott, 1986, p. 1073)

O feminismo tem um papel relevante na escrita de uma nova historiografia que possa enriquecer a narrativa histórica com perspectivas que inscrevam a mulher como agente no processo social, político, econômico. Colocando-se, retrospectivamente, numa posição de excluída, ela pode problematizar a visão do processo histórico como uma série de políticas de poder que ganham em ser vistas inter-relacionadamente, porquanto a questão de gênero atravessa todas as esferas do fenômeno social. Como se diz em Novas cartas portuguesas,

(...) a revolta da mulher é a que leva à convulsão em todos os extractos sociais; nada fica de pé, nem relações de classe, nem de grupo, nem individuais, toda a repressão terá de ser desenraizada, e a primeira repressão, aquela em que veio assentar toda a história do gênero humano, criando o modelo e os mitos das outras repressões, é a do homem contra a mulher. (Barreno, 2010 [1972], p.198)

Depois de 1980, tende-se para a rejeição do binarismo sexual como categoria de análise, à medida em que comportamentos sexuais que escapam à heteronormatividade problematizam a construção de gênero.

\footnotetext{
Instead of asking «what are the gender differences?» this approach (an approach which has been called post-structuralist or desconstructive feminist) leads one to ask «what differences does gender make?» and «how did gender come to make difference?» To argue that difference found in people's behavior, including their speech behavior, can simply be explained by invoking gender is to fail the question how gender is constructed. Instead, one needs to ask how and why gender differences are being constructed in that way, or what notion of gender is being normalized in such behavior. (Mcelhinny, 2004, p. 24)
}

Se o sistema gênero-sexo mostra a demarcação entre dois mundos, o masculino e o feminino, o próprio sistema linguístico, designadamente o portugês, em que o gênero gramatical masculino tem valência universal, dá conta de marcas de sexismo na língua. Longe da utopia da "neutralização de gênero" ou da androginia psicológica, desejada por Virginia Woolf, intelectuais como Rosi Braidotti, Drucilla Cornell ou Elisabeth Grosz sublinham a diferença sexual como 
categoria epistemológica, defendendo que "o objetivo do feminismo não é negar a diferença, mas recuperar o feminino na diferença sexual, gerar um imaginário de mulher autônomo, para lá dos estereótipos existentes da mulher." (Macedo, 2005, XXXIII) Os estudos feministas pós-coloniais revelaram-se uma área fértil para a conceituação da diferença, na medida em que, ao denunciarem a assimilação imposta aos povos e culturas não-europeias, propondo conceitos como hibridismo, mestiçagem ou crioulização, deslocaram a reflexão epistêmica para a troca cultural e para a forma como o colonizado assimilou a cultura estrangeira. Essa ideia de negociação e tensão entre línguas e culturas, que emigrou das perspetivas pós-coloniais, questiona justamente o universalismo cultural. Visto pela tradição como o outro cultural, compreende-se que o feminino se constitua como base de conceituação, revelando-se, por isso, de grande utilidade a noção de diferença na resistência ao discurso hegemônico:
A relação das mulheres enquanto minoria colonizada com o poder e o discurso dominante é muitas vezes significada por um hiato ou uma relação de estranheza, em consequência da própria intradutibilidade ou liminaridade da sua diferença, funcionando na comunidade social como um elemento de resistência ao processo homogeneizante. (Macedo, 2005, XXXIV)

Essa inscrição da mulher na cultura desestabiliza, pois, concepções canônicas do tecido sociocultural. Enquanto parte do grupo dos excluídos, ela pode problematizar a visão do processo histórico como uma série de políticas de poder que ganham em ser vistas interrelacionadamente, porquanto o sistema gênero-sexo atravessa todas as esferas da estruturação social. A escola do ressentimento, na formulação de Harold Bloom, o teórico da Grande Tradição, é o reduto das minorias, dos que, não fazendo um uso elevado da língua artística, adulteram o cânone. No entanto, como defende Maria Irene Ramalho, "(...) qualquer definição do que é 'melhor' ou 'correcto', isto é, qualquer definição do cânone tem de estar disponível para a redefinição." (Santos, 1994, p. 14)

Os estudos feministas dividem-se entre a crítica anglo-americana e a crítica francesa. A primeira centrou-se, essencialmente, nas relações da literatura com o cânone e com o estabelecimento do paradigma feminino, enquanto a segunda se debruçou sobre a questão da linguagem e do acesso feminino à esfera do simbólico, na linha do desconstrucionismo de Derrida, do estruturalismo e da psicanálise lacaniana. Assim, a produção cultural, a representação feminina na e pela linguagem, torna-se uma questão central nos estudos feministas, elaborada já na pioneira obra de Virginia Woolf, A room of one's own (1929), mais especificamente no ensaio "Women and fiction", onde a autora inglesa afirmava: "a women must have money and a room of her own if she is to write fiction" (p. 4). No universo anglo-saxônico - possivelmente pela circunstância de a Revolução Industrial ter forjado uma burguesia que elevou o individualismo a valor máximo, ao mesmo tempo em que submetia uma extensa massa da sociedade, o proletariado, a pesadas jornadas de trabalho, criando um sistema que daria origem ao capitalismo, mas que desenvolveria, igualmente, os seus anti-corpos -, a sociedade conheceu condições favoráveis à produção de uma literatura de autoria feminina.

Em The madwoman in the attic (1979), Sandra Gilbert e Susan Cubar debruçam-se sobre obras de escritoras do século XIX, com enfoque na questão da autoria e da autoridade literária, a partir da metáfora pena / pênis, para mostrarem a pretensa correspondência entre paternidade dos textos e possibilidade de criar como prerrogativa masculina, pois que a capacidade de gerar na mulher esgotar-se-ia na procriação.

A linguagem coloca-se para a mulher como uma questão de identidade, na medida em que, percebendo o mutismo a que foi, durante séculos, submetida, percebe também que o acesso às 
formas simbólicas da cultura e do poder se faz através da linguagem. Por isso, se as relações que o ser humano estabelece moldam a cultura, encarada, então, como produto histórico, então, necessariamente, as mulheres também têm um papel nessa construção. Interessa, sobretudo, compreender como se estabeleceram os mecanismos de consagração social e cultural que serviram à formação e consolidação do edifício social e cultural dominante e que atravessam todas as camadas de produção simbólica e de práxis social, desde o conhecimento à política ou à economia. Neste sentido, não poderá ser indiferente que seja uma mulher a escrever, se e quando utiliza a palavra, o faz para veicular perspectivas distintas daquelas que sustentam o discurso hegemônico. É evidente que, quando se fala de escrita feminina - écriture féminine, noção engendrada pela crítica feminista francesa nos anos 70, designadamente por Julia Kristeva, Hélène Cixous, Luce Iragaray e Monique Wittig - se pensa em marcas psicolinguísticas que revelem maneiras distintas de percepcionar a realidade e de integrar a experiência feminina na escrita. Com efeito, homem e mulher podem ter motivações semelhantes para escrever, mas será que os indivíduos do sexo masculino escrevem de determinada maneira e os do sexo feminino de outra? Não corresponderão esses estilos diferenciados (quando existem) a convenções, generalizações, que naturalizaram práticas estilísticas que derivam, antes de mais, de sedimentações culturais e históricas, mais do que revelam estruturas linguísticas características de indivíduos do sexo feminino ou masculino? Em O sexo dos textos, Isabel Allegro de Magalhães, pioneira nos estudos de gênero em Portugal, considerava que os textos estão "à partida condicionados pela perspectiva masculina presente no interior da língua." Mesmo se os estudos levados a cabo no âmbito da antropologia, sociolinguística, psicolinguística e áreas afins tendem a questionar uma identificação, uma relação de implicação, do gênero de quem escreve e da estrutura da língua, permanece o primado cultural na aprendizagem de papéis sociais, definidos em função da diferença sexual, possivelmente para se manter a ordem social, para regular os comportamentos dos indivíduos.

O ensaio seminal "Feminist criticism in the wilderness" (1981), de Elaine Showalter, lança as bases para o estabelecimento da crítica feminista enquanto paradigma conceitual que integra a experiência da mulher como modelo de interpretação do mundo: "It [feminist criticism] must find its own subject, its own system, its own theory, and its own voice.” (Showalter, 1981, p. 184) A produção literária de autoria feminina e a revisão do paradigma literário masculino fazem parte de um projeto complementar, o mesmo gesto que desafia a que se detectem eventuais marcas ou traços, ao nível das temáticas, das motivações, mas também de estruturas psicoafetivas reveladoras de especificidades masculinas ou femininas na escrita. Nesse ensaio, a estudiosa norte-americana coloca, também, a questão da existência de uma especificidade na literatura produzida por mulheres: "How can we constitute women as a distinct literary group? What is the difference of women's writing?" (Showalter, 1981, p. 185) Ana Luísa Amaral, coautora do Dicionário de crítica feminista português, num significativo artigo intitulado " ' O meu ofício é a circunferência': des-sexualizar o poético?”, pondera, nos seguintes termos, a existência de uma especificidade na poética feminina:

Se existe ou não uma escrita feminina, se essa questão é de impossível resposta, merecendo todavia ser debatida; como pode ela ser debatida; que fenómenos fazem, e quem produz, o cânone literário; por que razões se opta, no caso, por exemplo, da elaboração de programas para o ensino superior, quando se considera a leccionação e as limitações programáticas, por muito mais facilmente construir um programa em torno de textos escritos por homens do que em torno de textos produzidos por mulheres; como se constroem os pactos de leitura e por que é mais importante conhecer o sexo, se o texto for de uma escritora; porque, e se, mais afectados ficamos, caso saibamos que essa mulher pertence a uma minoria, seja ela rácica, intercultural ou sexual; se esse conhecimento altera a nossa 
forma de ler a sua produção literária; o que é literário, afinal, ou seja, circularmente retornando, quem produz e por que fenómenos ele se rege, o cânone literário - são aspectos que me parecem demasiado relevantes para continuarem a ser ignorados por uma parte ainda significativa da academia portuguesa. (Amaral, 2004, p. 23)

"Parler femme" [falar (como) mulher] - a formulação de Luce Irigaray dá conta da relação entre corpo e escrita feminina, ideia que informa a crítica francesa dos anos 70. A libertação do corpo feminino, sexualmente reprimido, e a transgressão ao nível da expressão linguística, terreno do masculino e da cultura homológica e patriarcal, parecem estar na origem dessa necessidade de constituição íntegra de uma "nova mulher", como querem Novas cartas portuguesas, livro de autoria coletiva de Maria Isabel Barreno, Maria Teresa Horta e Maria Velho da Costa, publicado em 1972 e imediatamente confiscado pela censura, alegadamente por "atentado à moral pública e pornografia”, de acordo com a Constituição Portuguesa da época. Escrever o corpo, falar do desejo feminino, das ânsias, aspirações e sentimentos da mulher, equivale a partir à descoberta da sua identidade, à exploração de si própria. É como se lhe fosse necessário cartografar-se para afirmar a sua subjetividade, o seu eu, e a apreensão da realidade com base nessa experiência. Essa parece ser também a razão por que a produção de autoria feminina insiste na reflexão sobre o ato da escrita: “(...) uma grande proporção da poesia de mulheres é sobre o direito à palavra e à escrita. (...) Ser mulher e poeta representa para muitas mulheres poetas uma profunda ruptura entre a sua identidade social e sexual e a sua prática artística (....)." (Kaplan apud Macedo, 2005, p. 53) Escrever o corpo equivale a inscrever a feminilidade na cultura contra uma objetificação da mulher, como se o corpo fosse uma fonte de onde emana uma escrita que é como um fluido corporal, íntima e intrínseca. Elaine Showalter assinala as virtudes da biocrítica, mas adverte:

The study of biological imagery in women's writing is useful and important as long as we understand that factors other than anatomy are involved in it. Ideas about the body are fundamental to understanding how women conceptualize their situation in society; but there can be no expression of the body which is unmediated by linguistic, social and literary structures. The difference of woman literary practice, therefore, must be sought (in Miller's words) in "the body of her writing and not the writing of her body". (Showalter, 1981, p.190)

A consciência de usurpação do terreno poético masculino domina a criação estética de Florbela Espanca, para falarmos do universo literário português:

Li o livro e não me desagradou, embora aquela poesia seja tudo quanto há de menos artístico e literário; é como a minha, talvez, e como a de dezenas de mulheres na nossa situação. Poetas por instinto, sem mestres, sem escola, sem método, sem norte, podemos apenas cantar, sonhar e chorar, nunca fazer versos! Versos chamo eu aos de G. Junqueiro, aos do Augusto Gil, aos de António Nobre. São lá versos aquilo que nós escrevemos! (apud Klobucka, 2009, pp. 97-98 )

Para a autora de Soror Saudade, os textos escritos por mulheres não têm valor literário, surgindo a escrita feminina, consequentemente, como uma anomalia, expressão intimista e catártica. Apesar disso, a sua própria escrita inscreve-se nos interstícios da cultura literária masculina, como queria o projeto feminista.

Hélène Cixous reconhece a quase inexistência de textos que exemplifiquem o que designa "écriture féminine". No entanto, como refere Showalter, "the concept of écriture féminine provides a way of talking about women's writing which reasserts the value of the feminine and identifies the theoretical project of feminist criticism as the analysis of difference". (Showalter, 1986, p. 186) A faculdade linguística feminina é frequentemente associada ao mistério, ao intraduzível, visão presente na linguagem do mito, que apresenta a mulher como a sibila, por exemplo. Para esta concepção da suposta ininteligibilidade da expressão feminina contribuiu a 
narrativa mítica masculina. Na verdade, tais percepções só denunciam o mutismo ou exclusão cultural da mulher, encerrada na esfera da domesticidade. Assim, estudos levados a cabo por linguistas atribuem diferenças discursivas na expressão feminina ou masculina a questões estilísticas, a estratégias discursivas ou contextuais: "language and style are never raw and instinctual but are always the products of inummerable factors, of genre, tradition, memory and context." (Showalter, 1981, p. 193) Por isso, a tônica na abordagem da questão linguística deve ser posta no acesso feminino à linguagem, nos interditos internalizados e na exploração de uma linguagem liberta de tais constrangimentos: "Rather than wishing to limit women's linguistic range, we must fight to open and extend it." (Showalter, 1981, p. 193)

Novas cartas portuguesas impõem-se, desde logo, como exercício a três, desestabilizando concepções de autoria e de autoridade textual, denunciando a cultura patriarcal, afirmando uma visão feminina, alternativa, da realidade, impondo-se como escrita de mulheres, abertamente desafiadora. Neste sentido, parecem mostrar um caminho para o que seria uma escrita descentrada, o que seria "escrever com o vigor de mulher[es]". No ano em que se comemoram os 40 anos da primeira edição de Novas cartas portuguesas, interessa perceber como, para além do emblema do feminismo em Portugal, Novas cartas inauguraram uma prática de revisão do cânone nacional, ao (re)lerem o texto seiscentista Lettres Portugaises, o que, simbolicamente, parece sugerir esse roubo do fogo prometeico, o "roubo da palavra", nos termos de Simone de Beauvoir, e a resistência feminina. E as possibilidades de revisão do cânone literário de tradição masculina permitem a emergência e a visibilidade de uma linhagem de autoria feminina em Portugal.

As abordagens críticas de que têm sido alvo Novas Cartas revelam-se insuficientes para valorizarem a sua importância como marco de uma nova literatura produzida por mulheres em Portugal, obra que, de maneira privilegiada, possibilita a releitura do cânone literário português que as ferramentas teóricas da Crítica Feminista permitem operacionalizar, à semelhança do que aconteceu com A room of one's own, de Virginia Woolf. Se Novas cartas portuguesas é, consensualmente, uma obra de referência (veja-se o ensaio fundamental de Maria Alzira Seixo "Quatro Razões para reler Novas cartas portuguesas") - com várias edições (nove), sendo a última (a 1. a anotada) de novembro de 2010, pela importante poeta e intelectual Ana Luísa Amaral -, por que razão os contributos ocasionados pela Crítica Feminista, que permitiriam ler, a uma nova luz, a literatura produzida em Portugal nas últimas décadas, não têm suficiente visibilidade em Portugal? Se existe uma importante plêiade de escritoras no país, não será pertinente reconhecer essa tradição e estabelecer-lhe uma genealogia? Novas cartas referem-se explicitamente a uma "linhagem feminina oposta ao esquecimento e à diluição" (p. 139), que se concebe, significativamente, como irmandade: "Considerai, irmãs minhas, cá hoje (...)” (p. 6); "Ouvem já, entre isto e o traçado eu cada uma trama em suas vidas, (...) instaurando a lei de uma nova irman(dade) - dão-se conta do risco?” (p. 29)

Remontando a Mariana Alcoforado, autora da correspondência amorosa que ingressou na história da literatura barroca em Portugal como um ícone, passando por Marquesa de Alorna, introdutora do Romantismo em terras lusitanas; na época contemporânea, por Florbela Espanca, que abriu um solitário caminho feminino para o Modernismo português, apartada como esteve dos representantes mais ilustres de Orpheu, Sophia de Mello Breyner, Natália Correia, Agustina Bessa-Luís, Judite de Carvalho, Maria Teresa Horta, Maria Isabel Barreno, Maria Velho da Costa, Lídia Jorge, Teolinda Gersão, Luiza Neto-Jorge, Ana Luísa Amaral, Adília Lopes, Inês Pedrosa e tantas outras, a literatura portuguesa protagonizada por mulheres configura uma genealogia assinalável. 
De caráter deliberadamente excessivo, como assinala Maria de Lourdes Pintassilgo, que prefacia a primeira edição, Novas cartas repercutiram no meio sociopolítico português e serviram à denúncia de todo o tipo de "clausura" ideológica: violência doméstica contra as mulheres, obscurantismo, pobreza, analfabetismo, aborto clandestino, desigualdades sociais, a sociedade patriarcal e sexista que mantém as mulheres numa posição de subalternidade em relação aos homens. Novas cartas revelavam, pois, dissensões internas na sociedade portuguesa bem pensante, refratária aos valores vigentes. Nesta conjuntura pré-revolucionária, a questão feminista adquiriu relevância em Portugal, tendo as autoras recebido o apoio de eminentes feministas da cena internacional, como Simone de Beauvoir, Iris Murdoch, Marguerite Duras, Doris Lessing ou Christiane Rochefort.

Estas cartas novecentistas recuperam as seiscentistas, supostamente de autoria da famosa freira portuguesa de Beja, Mariana Alcoforado, que teria endereçado ao Cavaleiro de Chamilly cinco cartas apaixonadas (publicadas, pela primeira vez em francês e em França, em 1669, só vertidas para português em 1819), as quais repercutiram enormemente na literatura nacional, mas também universal, a julgar pelas edições que surgiram noutros países e que tematizam o amor incondicional da freira pelo marquês. Para além de verem na figura de Mariana Alcoforado uma precursora, uma mulher autora cuja correspondência amorosa ingressou na história da literatura barroca nacional como referência incontornável, as Três Marias aproveitam o potencial lendário da história da freira e as possibilidades de leitura ideológica e transgressora que o texto-fonte já evidenciava, para relançarem temas polêmicos que noutros países, como a França ou os Estados Unidos, eram carros-chefe das lutas feministas.

Uma das temáticas fundamentais de Novas cartas diz respeito à sexualidade feminina, ao direito que a mulher, "latifúndio herdado" do homem, tem de dispor do próprio corpo e de ser sujeito de desejo. Ora, a questão do sexo e a "produção de verdade sobre o sexo" é eminentemente política e está ao serviço da "tecnologia da sexualidade", como mostra Foucault, na emblemática História da sexualidade. Conscientes de que poder e sexo estão intimamente ligados e de que a palavra constitui um interdito (tenha-se presente a sociedade portuguesa da época, regulada pelos valores Deus, pátria e família), as Três Marias exploram a temática da sexualidade feminina, não como exposição da feminilidade e do corpo feminino enquanto objeto do desejo masculino, mas sobretudo falam do desejo, do prazer e da intimidade feminina.

"O corpo" é um dos 120 textos de Novas cartas portuguesas, obra heteróclita que reúne composições de diferentes tipologias, embora agrupadas sob o nome genérico de cartas (gênero intimista e menor, associado, na história literária, à escrita doméstica e, portanto, feminina). Trata-se de um texto em prosa poética, de grande economia vocabular, sendo a repetição de palavras um recurso fundamental que faz com que o signo verbal se mostre na sua natureza de signo, na sua espessura e materialidade:

O corpo

Ali estava o seu corpo adormecido, aninhado no seu descanso, tão quieto, tão presente na luz amarelada, definindo-se por seu peso e por aquele estar quieto, todo tomado de luz, sem contorno que separasse corpo e luz, os músculos lisos debaixo da pele, tão escorridos na presença quieta, quase diluídos, ninho de seu próprio descanso, prolongando os lençóis desfeitos e suas curvas frouxas de fadiga, e a cova morna do colchão, e a luz quieta e densa como pele amarela sobre a outra, enchendo o quarto até ao tecto e às paredes, absorvendo em si, como corpos amáveis naquele sono, o candeeiro e a mesa baixa e os livros e as roupas, todo o quarto feito camadas sucessivas de luz e substância variada rodeando o centro, núcleo de respirar muito brando, e a tudo se propagando esse único e muito brando movimento, a pele doirada estendendo-se um pouco, no peito alto, de curva possante e com seus 
mamilos quase rosados, e as costas movendo-se também com a mesma unida e certa ondulação da água mansa, as costas bem talhadas, estreitando-se do largo dos ombros até à anca com a rectidão da pedra talhada, mas de braço a braço a curva bombeada, alta e suave, que a meio se cava bruscamente como o leito dum rio, e movendo-se ainda o osso da anca, delicado, anguloso, saliente agora de sua habitual discrição no corpo que repousa de lado e se debruça, leve, cavando um pouco a cintura, escondendo o ventre e a densa doçura dos pêlos mornos, e um pouco o sexo, alteando o redondo no entanto severo, cinzelado - das duas nádegas estreitas, aparecendo depois o sexo entre as duas pernas que se abrem, uma estendida sobre a cama e a outra levemente flectida, esvaindo-se a coxa da anca alteada até à cama, onde o joelho pousa, e aí segue a perna tão abandonada no lençol que quase o fere com seu peso, e entre as coxas, renascendo da sombra do ventre escondido, e que se estende como savana cálida, que em si retém o amarelo da luz, na curva nascente das nádegas, nas coxas, nas pernas, entre as coxas o seu sexo, os dois pequenos pomos cuja firmeza se desenha na pele branda e a corola recolhida de seu pénis adormecido. (Barreno, [1972] 2010: 175)

O texto desenvolve-se numa frase única, por coordenação. As formas verbais gerundivas fazem o texto progredir sintaticamente e o léxico estabelece uma constelação de signos que se retomam anaforicamente. O predomínio de vocábulos da mesma vizinhança paradigmática, que se declinam no texto num processo de imitação interna, endofórica, dotam o discurso de uma espécie de inteligência isomórfica: amarela / amarelada, alto / alteando / alteada. Convém, agora, questionar o lugar de onde é representado este corpo, como se sugere a presentificação deste corpo que a leitura acompanha em seus movimentos lânguidos. O sujeito observador não se revela, mas é possível sentir a presença do seu olhar, que se demora, com gozo, naquele corpo. Aliás, a sua presença trai-se no advérbio "ali" e no pronome possessivo "seu” - "seu corpo" -, que denunciam o lugar da enunciação e da observação, mas não se sabe nada a seu respeito nem do sujeito representado. O movimento do corpo é também o movimento do signo que, do caráter geral (símbolo), no título, passou a existente concreto (índice) e a ter um caráter vago de qualidade (ícone), para aplicarmos os pressupostos da teoria peirciana. Tal rarefação não corresponderia ao esvaziamento do signo corpo, sobretudo feminino, fixado nas imagens literárias e cinematográficas como objeto de desejo, coisificado, despido pelo olhar voyeur masculino? Esta é a primeira hipótese de leitura. Só no final do texto o surpreendente aparecimento da palavra "pénis" subverte a interpretação. Se a "chave" de leitura se resolve por uma ironia subversiva de cunho feminista, diríamos, que inscreve um olhar feminino no lugar do voyeur e um corpo masculino no de objeto de desejo, inscrito num texto de cunho feminista que justamente questiona o cânone literário, as imagens cristalizadas da mulher nos textos escritos por homens, então justifica-se pensar numa proposta de ressignificação do signo, pois o corpo, tomado como categoria geral, admite qualquer um dos sexos. O que se questiona, afinal de contas, parece ser é o binarismo masculino / feminino, que constrói estereótipos com base na diferença sexual. Por isso, em última análise, o que está em causa é a forma como se olha, como a construção de gênero corresponde a convenção. Haveria estratégia mais eficiente do que o esvaziamento, substituição de um signo por outro, de um sinal por outro, refazendo-se a ligação entre signo e objeto? Portanto, é a lei, a convenção, que este olhar quer fazer o leitor-voyeur questionar. Ao substituir-se o signo esperado "vulva” por um outro que é igualmente possível, sugere-se que são equivalentes, comutáveis, que um pode estar no lugar do outro. Num nível mais elementar de interpretação, passa a mensagem de que a mulher também é sujeito que deseja e não só objeto de desejo por parte do homem, sendo a cena construída por forma a criar uma expectativa falsa ou desorientadora, mas também desconcertante, se pensarmos num leitor do sexo masculino que, perversamente, é, qual voyeur, levado a contemplar, desejante, um corpo que supõe feminino e que, para mais, permanece efeminado. Aliás, está adormecido, isto 
é, anulado na sua possibilidade viril - “corola recolhida”, "pénis adormecido”. Uma espécie de vingança feminina... ou feminista...

O que se propõe com esta inversão é esvaziar o signo, saturado no convencionalismo das imagens do corpo feminino que as mulheres não construíram, e que um olhar primeiro, inaugural, poético, pode resgatar, revelar. Na verdade, parece querer-se refazer a própria semiose, ao implicar-se um observador-intérprete que, inscrito no próprio texto, aponta para um objeto que é um signo verbal, convenção por excelência. Questionando-se esta semiose, propõe-se uma outra. Afinal, se, como dizia Simone de Beauvoir, "on ne naît pas femme, on le devient", o mesmo se poderia dizer do homem: o sujeito não nasce homem, torna-se. A diferença sexual teria dado origem à convenção de comportamentos e papéis sexuais masculinos ou femininos. Aliás, uma das bandeiras do feminismo atual reside no questionamento da heteronormatividade sexual, que define papéis sexuais em função do fim reprodutor.

A arte, na sua função desalienadora, pode contribuir para o estabelecimento de um diálogo social mais amplo, inscrevendo o lugar de sujeitos cujas perspectivas foram negligenciadas e, por conseguinte, plasmar nas obras possibilidades alternativas ao discurso dominante que, sem serem necessariamente utópicas, ampliam o pensamento sobre a condição de ser pessoa a conceituações mais generosas e humanizadoras.

\section{REFERENCIAS BIBLIOGRÁFICAS:}

AMARAL, Ana Luísa. Desconstruindo Identidades: ler Novas cartas portuguesas à luz da teoria queer. In: Cadernos de literatura comparada 3/4. Porto: Granito, 2001.

. Do centro e da margem: escrita do corpo em escritas de mulheres. In: Cadernos de literatura comparada 8/9. Porto: Granito, 2003. . 'O meu ofício é a circunferência': des-sexualizar o poético?. In: ex-aequo

9, 2004, 19-35.

BARRENO, Maria Isabel; HORTA, Maria Teresa; COSTA, Maria Velho. ed. anotada. Ana Luísa Amaral (org.). Novas cartas portuguesas. Alfragide: D. Quixote, [1972] 2010.

BEAUVOIR, Simone de. O segundo sexo. Trad. Sérgio Millet. Vol. I-II. Venda Nova: Bertrand, 1987. GILBERT, Sandra M.; GUBAR, Susan. The madwoman in the attic: the Woman writer and the nineteenth-century literary imagination. New Haven e Londres: Yale University Press, 1984. KLOBUCKA, Anna. O Formato Mulher: a emergência da autoria feminina na poesia portuguesa. Coimbra: Angelus Novus, 2009.

LACAN, Jacques. Le Séminaire XX: Encore (1972-73). Paris: Éditions du Seuil, 1975. MACEDO, Ana Gabriela; AMARAL, Ana Luísa (orgs.). Dicionário da crítica feminista, Porto: Edições Afrontamento, 2005. MAGALHÃES, Isabel Allegro de. O sexo dos textos: traços da ficção narrativa de autoria feminina, Lisboa: Editorial Caminho, 1995.

MCELHINNY, Bonnie. Theorizing gender in sociolinguistic and linguistic anthropology. In: The handbook of language and gender (org. Janet Holmes and Miriam Meyerhoff). Blackwell Reference Online, 2004.

NÖTH, Winfried. Panorama da semiótica: de Platão a Peirce. 3 ed. São Paulo: Annablume, 2003. RAMALHO, Maria Irene Ramalho; RIBEIRO, António Sousa (orgs.). Entre ser e estar: raízes, percursos e discursos da identidade. Porto: Edições Afrontamento, 2002. SANTOS, Maria Irene Ramalho de Sousa. O cânone nos estudos anglo-americanos. In: O cânone nos estudos anglo-americanos (org. Isabel Caldeira). Coimbra: Minerva, 1994, pp. 11-29. 
SCOTT, Joan. W. Gender: a useful category of historical analysis. In: The american historical review, Vol. 91, n. 5. American Historical Association: 1986. Disponível em: <http:/l www.jstor.org/stable/1864376 >. Acesso em 15 jun 2011.

SEIXO, Maria Alzira. "Quatro razões para reler Novas Cartas Portuguesas”. 1998. Disponível em: 〈http://www.ciberkiosk.pt/arquivo/ciberkiosk4/seixo.htm〉. Acesso em 07 jun 2011.

SHOWALTER, Elaine. Feminist criticism in the wilderness. In: Critical inquiry, Vol. 8, n.2, Writing and sexual difference, 1981. Disponivel em: <http://www.jstor.org/ stable/1343159>. Acesso em 20 jun 2011.

SHOWALTER, Elaine. 'A Literature of their own' revisited. In: A forum on fiction, Vol. 31, n.․ 3. 1998. Disponível em: <http://www.jstor.org/stable/1346107>. Acesso em 15 jun 2011.

WOOLF, Virginia. A room of one's own. England: Penguin Books, 2004.

\section{ARTIGO RECEBIDO EM: $01 \mathrm{feV} .2012$}

ARTIGO ACEITO EM: 19 mar. 2012

Referên I A eletrôn I ca: CunHA, Paula Cristina Ribeiro da Rocha de Morais. Da Crítica Feminista e a Escrita Feminina. Revista Criação \& Crítica, n. 8, p. 1-11, abr. 2012. Disponível em:<http://www.fflch.usp.br/dlm/ criacaoecritica/dmdocuments/CC_N08_PCRRMCunha.pdf >. Acesso em dd mmm aaaa. 